\title{
The TRH Stimulation Test in Alzheimer's Disease and Major Depression: Relationship to Clinical and CSF Measures
}

\author{
Susan E. Molchan, Brian A. Lawlor, James L. Hill, \\ Alan M. Mellow, Candace L. Davis, Rick Martinez, \\ and Trey Sunderland
}

\begin{abstract}
A blunted thyroid-stimulating hormone (TSH) response to exogenous thyrotropin-releasing hormone (TRH) has been reported to occur consistently in patients with major depression and less consistently in patients with Alzheimer's disease (AD). In this study we compared the TSH response to TRH in a large group $(\mathrm{n}=40)$ of $A D$ patients, elderly patients with major depression $(\mathrm{n}=17)$, and age-matched controls $(\mathrm{n}=14)$ to further characterize how it may relate to clinical variables, baseline thyroid function tests, and cerebrospinal fluid measures. Comparisons of TRH stimulation test response across all three groups revealed that patients with major depression had lower stimulated TSH levels ( $\triangle \max T S H)(\mathrm{p}<0.02)$ and higher (though still within normal limits) mean thyroxine $\left(T_{4}\right)$ levels $(\mathrm{p}<0.05)$ than the $A D$ patients or controls. AD patients with a blunted TSH response had a significantly higher mean free $T_{4}\left(F T_{4}\right)$ level $(\mathrm{p}<0.03)$ and tended to be more severely demented $(\mathrm{p}<0.01)$ than those with a nonblunted response.
\end{abstract}

\section{Introduction}

Neuroendocrine tests such as the dexamethasone stimulation test and the thyrotropinreleasing hormone (TRH) stimulation test have been examined in patients with various neuropsychiatric disorders as a possible window to the underlying neurotransmitter pathophysiology (Loosen 1987). This idea is complicated by the interacting regulatory and feedback mechanisms present in the body for each neurotransmitter and each associated hormonal signal (Loosen 1987). Still, it is felt that neuroendocrine tests may give us clues regarding the pathophysiology and course of certain disorders or symptoms, particularly in delineating different biological subgroups of neuropsychiatric disorders. The study of neuroendocrine abnormalities in Alzheimer's disease (AD) may be of particular

From the Unit on Geriatric Psychopharmacology, Laboratory of Clinical Science, National Institute of Mental Health, Bethesda. MD (SEM. JLH, RM, TS), the Division of Geropsychiatry, Department of Psychiatry, Mount Sinai School of Medicine, New York, NY (BAL), the Department of Psychiatry, University of Michigan Medical Center, Ann Arbor. MI (AMM). and the Section on Behavioral Endocrinology, Biological Psychiatry Branch. National Institute of Mental Health, Bethesda, MD (CLD).

Address reprint requests to Süsan E. Molchan, M.D., NIH Clinical Center, 9000 Rockville Pike, Building 10, Room 3D41, Bethesda, MD 20892.

Received February 5, 1991; revised May 17, 1991 
interest, in that alterations in neurotransmitters and their metabolites have already been studied extensively in plasma, CSF, and postmortem brains, making AD one of the most well-characterized neuropsychiatric illnesses in terms of specific pathology and associated neurochemical changes (Perry 1987).

A blunted thyroid-stimulating hormone (TSH) response to intravenously administered TRH has been reported to occur in 25\%-75\% (depending on the cutoff value used to define a blunted TSH response) of patients with major depression (Loosen 1987). Patients with major depression and $\mathrm{AD}$ often have overlapping clinical symptoms (Reding et al 1985; Reifler et al 1986), and studies of the TRH stimulation test in AD have shown that up to $47 \%$ of patients have a blunted TSH response (Sunderland et al 1985; Thomas et al 1987). Other researchers have reported no blunting of the TSH response to TRH in AD patients (El Sobky et al 1986; Peabody et al 1986; Franceschi et al 1988; Lampe et ai 1988; Warner et al 1990). To help clarify the ongoing scientific debate concerning the TRH stimulation test in AD, we studied the TSH response to TRH in a large group of AD patients, a group of elderly patients with major depression, anu age-matched normal controls. Given the substantial number of AD subjects in this study, we also examined the TSH response with reference to clinical and biological characteristics including baseline thyroid function tests (TFTs), CSF monoamine metabolites, and CSF somatostatinlike immunoreactivity (SLI).

\section{Subjects and Methods}

Fifty patients with probable AD, 21 older patients diagnosed with major depression, and 18 age-matched controls participated in the study. Probable primary degenerative dementia of the Alzheimer type and major depression were diagnosed according to DSM-IIIR criteria (American Psychiatric Association 1987). In addition, patients diagnosed with major depression had a history of prior depressive episodes, had no significant cognitive impairment, and recovered after treatment with antidepressant medication or electroconvulsive therapy. Some of the AD patients had prior or concurrent depressive symptoms, but the dementia was established as the primary diagnosis. Significant medical problems were ruled out in all patients and controls by physical examination and laboratory tests. Normal controls were screened to exclude any personal or significant family history of medical, cognitive, or psychiatric disorder. Controls were recruited from the community and paid for their participation. All subjects gave written informed consent prior to participation in the study (for AD patients, a relative aiso signed the consent form). The $\mathrm{AD}$ and major depression patients were studied during hospitalization at the NIMH and the normals as outpatients; all tests and ratings were done within a 3-week period. Subjects were free of all psychotropic medications for at least 3 weeks prior to participation.

The TRH stimulation test was done between 8:30 and 10:30 AM after an overnight fast. An 18-gauge catheter was inserted into an antecubital vein and baseline blood samples were collected through the catheter at least $20 \mathrm{~min}$ after IV insertion. After collection of the -15 and 0 time point samples, $0.5 \mathrm{mg}$ of TRH (Protirelin) was administered as an IV bolus. Subsequent blood samples were collected 15, 20, 30, and $45 \mathrm{~min}$ following the TRH injection. TSH levels were determined by double-antibody radioimmunoassay (RIA) by the NIH Clinical Center laboratory (normal range 0.4-4.6 $\mu \mathrm{IU} / \mathrm{ml}$ ). The coefficients of variation for this assay for low, midrange, and high concentrations are $6.2 \%$, $5.1 \%$, and $5.0 \%$, respectively. Baseline TFTs and TSH levels were measured in serum, on the day in which they were collected. Triiodothyronine $\left(\mathrm{T}_{3}\right)$ (normal range 88-162 
Table 1. Clinical Data un Alzheimer's Disease Patients $(n=40)$

\begin{tabular}{lc}
\hline \multicolumn{1}{c}{ Clinical measure } & Mean $=$ SD \\
\hline Illness duration (yr) & $3.8 \pm 2.1$ \\
Dementia severity & $1.7 \pm 0.7$ \\
Clinical Dementia Rating & $4.5 \pm 0.9$ \\
Global Deterioration Scale & $68.0 \pm 13.0$ \\
Wechsler Memory Scale & $19.5 \pm 10.5$ \\
DMAS (17 item) & \\
Bunney-Hamburg Global Scales & $3.4 \pm 1.7$ \\
Depression & $4.2 \pm 1.9$ \\
Anxiety & $4.6 \pm 2.2$ \\
Sadness & $2.7 \pm 1.8$ \\
Anger & $1.7 \pm 1.3$ \\
Psychosis &
\end{tabular}

Dementia Mood Assessmemt Scale.

$\mathrm{ng} / \mathrm{dl}$ ) and free $\mathrm{T}_{4}\left(\mathrm{FT}_{4}\right)$ (normal range $1.0-2.1 \mathrm{ng} / \mathrm{dl}$ ) were measured by $\mathrm{RIA}$, and thyroxine $\left(\mathrm{T}_{4}\right)$ (normal range $5.0-10.0 \mu \mathrm{g} / \mathrm{dl}$ ) by fluorescence polarization immunoassay.

Dementia severity was rated using the Clinical Dementia Rating (CDR) (Hughes et al 1982) and the Global Deterioration Scale (GDS) (Reisberg et al 1982). The degree of depression in the AD patients was evaluated using the Dementia Mood Assessment Scale (DMAS) (Sunderland et al 1988a, 1988b), a 24-item scale, the first 17 of which were designed to measure depression in dementia patients; the last 7 items measure cognitive and functional impairment. The Bunney-Hamburg Global Behavioral Rating Scales were used to evaluate aspects of behavior, mood, and impairment (Bunney and Hamburg 1963; Sunderland et al 1988a) in both patient groups. The depressed patients were also evaluated with the Hamilton Depression Scale (Hamilton 1960).

Lumbar punctures (LPs) were done between 8:00 and 9:00 AM, in the lateral decubitus position, after an overnight fast. Subjects were on bed rest prior to the LP, except for voiding. CSF from early aliquots was frozen at $-70^{\circ} \mathrm{C}$ and later used for measurement of the neurotransmitter metabolites 3-methoxy-4-hydroxyphenylglycol (MHPG), 5-hydroxyindoleacetic acid (5-HIAA), and homovanillic acid (HVA), as described elsewhere (Scheinen et al 1983). The 26th $\mathrm{ml}$ of collected CSF was inmediately frozen without preservatives on dry ice and stored at $-70^{\circ} \mathrm{C}$ for later measurement of SLI by RIA, as described elsewhere (Ruhinow 1986).

\section{Data Analysis}

For comparisons among subject groups, data were analyzed using subjects with completely normal baseline TFTs (Table 1), unless otherwise specified. Subjects with TFTs outside of the normal range were excluded in order to standardize conditions for the analysis of TRH stimulation test results as much as possible, so that results would better refiect changes related to the illnesses being studied, rather than primary thyroid conditions, in view of the high prevalence of thyroid abnormalities in the elderly (Targum et al 1989). Between-group differences in age, baseline TFTs, and the mean maximum increase of TSH ( $\Delta$ maxTSH) from the mean baseline value (the sum of the values at the -15 and 0 time points, divided by 2 ) were evaluated using one-way analysis of variance (ANOVA) and post hoc $t$-tests. 
The time course of the TSH response to TRH was compared among groups using repeated-mcasures ANOVA, followed by one-way ANOVAs accompanied by post hoc $t$-tests at each time point. Also, the area under the curves (AUC) of the TSH response to TRH among subject groups was compared using one-way ANOVA and post hoc ttests. Missing data points (2\%) for the time course and AUC analyses were estimated by linear interpolation.

"Blunted" when used in the text refers to $\Delta$ maxTSH levels of $\leqslant 7 \mu \mathrm{IU} / \mathrm{ml}$, unless otherwise specified. Fisher's exact test was used to compare the rate of blunted responses (using cutoff values of both $\leqslant 7 \mu \mathrm{IU} / \mathrm{ml}$ and $\leqslant 5 \mu \mathrm{IU} / \mathrm{ml}$ ) among diagnostic groups (Loosen 1987). One-tailed statistics were used based on prior studies showing either a blunted response, or no difference from normais in AD and depressed patients. One-way ANOVA and post hoc $t$-tests were used to compare mean $\Delta$ maxTSH between genders, within and among diagnostic groups. Differences in baseline TFTs, TSH response, and clinical variables were examined between genders and between blunters and nonblunters within each diagnostic group by $t$-tests (two-tailed). A correlation (Pearson's) matrix was generated to explore possible relationships between the clinical and biological variables.

Results

Ten AD patients had abnormal baseline TFTs; most of these had a slightly elevated baseline TSH. Two depressed patients and two normal controls had an elevated baseline TSH, and two in each of these groups had an elevated FT 4 . Therefore, 10 of $50(20.0 \%)$ AD. 4 of $21(19.0 \%)$ depressed, and 4 of $18(22.2 \%)$ control subjects had baseline TFT abnormalities, and were therefore excluded from further analyses. These numbers are consistent with prior studies showing that the prevalence of thyroid abnormalities is not significantly different between AD patients and controls (Lawlor et al 1988).

When all subjects (including those with abnormal baseline TFTs) are included, the rates of blunting are as follows: 11 of $50(22.0 \%)$ of the AD patients $(p<0.26$ different from normals), 9 of $21(42.9 \%)$ of the depressed patients $(p<0.03$ different from normals, $p<0.07$ different from AD patients), and 2 of $18(11.1 \%)$ of the normals. When those subjects with normal TFTs were compared (Table 1), the group of patients with major depression had a higher rate of TSH blunting than the normals (7 of 17 [41\%] versus 1 of $14[7 \%], p<0.04$ ). The rate of blunting in the AD group (11 of 40 , or $27.5 \%)$ differed from normals at a trend level of significance $(p<0.10)$ and did not differ from that of the depressed group $(p<0.24)$ (Table 3 ). When a cutoff of $\leqslant 5 \mu$ IU/ $\mathrm{ml}$ was used for $\Delta \operatorname{maxTSH}, 6$ of $40(15 \%)$ ( 4 men, 2 women) of AD patients $(p<0.10$ different from normals), 5 of 17 (29.4\%) (4 men, 1 woman) of depressed patients ( $p<$ 0.04 different from normals, $p<0.18$ different from AD patients), and no normals had a blunted response.

The major depression patients had a significantly lower mean $\Delta \max T S H(F[2,70]=$ $4.96, p<0.01)$ than both the AD patients $(p<0.003)$ and the elderly controls $(p<$ 0.02 ) (Table 2). Repeated-measures ANOVA revealed an overall significant difference between subject groups (group $\times$ time interaction $F[2.6,88.5]=4.38, p<0.01$ ) for the time course of the TSH response to TRH shown in Figure 1. This overall difference resulted because stimulated TSH levels in the depressed group were significantly lower at all time points than those of both the $A D$ and normal subjects, who did not differ from each other. The trend towards a significant difference in AUC $(F[2,68]=2.94, p<$ 
Table 2. Demographic and Biological Data on Patients and Normal Controls

\begin{tabular}{lccc}
\hline \multicolumn{1}{c}{ Variable } & $\begin{array}{c}\text { Alzheimer's Disease } \\
(n=40)\end{array}$ & $\begin{array}{c}\text { Major } \\
\text { Depression } \\
(n=17)\end{array}$ & $\begin{array}{c}\text { Normal } \\
\text { Controls } \\
(n=14)\end{array}$ \\
\hline Age $(\mathrm{yr})$ & $64.2 \pm 7.8$ & $65.8 \pm 8.1$ & $62.3 \pm 8.1$ \\
Gender & $25 \mathrm{M} .15 \mathrm{~F}$ & $8 \mathrm{M}, 10 \mathrm{~F}$ & $9 \mathrm{M}, 6 \mathrm{~F}$ \\
$\Delta \max$ TSH $(\mu \mathrm{IU} \mathrm{nd})$ & $12.8 \pm 6.1$ & $7.0 \pm 6.7^{\circ}$ & $12.5 \pm 6.7$ \\
Baseline $\mathrm{TSH}(\mu \mathrm{lU} / \mathrm{ml})$ & $2.6 \pm 1.2$ & $2.3 \pm 1.2$ & $2.7 \pm 1.2$ \\
Total $\mathrm{T}_{4}(\mu \mathrm{g} / \mathrm{dl})$ & $7.8 \pm 1.0$ & $8.9 \pm 1.3^{a}$ & $7.5 \pm 1.4$ \\
Free $\mathrm{T}_{4}(\mathrm{ng} / \mathrm{dl})$ & $1.4 \pm 0.4$ & $1.7 \pm 0.4^{a}$ & $1.4 \pm 0.4$ \\
$T_{3}(\mathrm{ng} / \mathrm{dl})$ & $125.8 \pm 25.5$ & $122.4 \pm 25.5$ & $119.5 \pm 26.4$ \\
\hline
\end{tabular}

$a_{p}<0.05$ different from Alzheimer's patients and controls.

0.06) also resulted because the depressed patients had a s.naller area than both the $A D$ and normal subjects.

Table 2 summarizes mean baseline TFT data for all subjects. Baseline TFT date on patients with a blunted as compared with a nonblunted response is summarized in rable 3. Table 4 summarizes TSH response and baseline TFTs by gender. Comparison of mean $\Delta$ maxTSH of female subjects among diagnostic groups revealed statistically significant differences $(F[2,26]=3.43, p<0.05)$; paired comparisons were significant only between the depressed and control groups $(p<0.05)$ (Table 4). Significant differences of $\Delta \operatorname{maxTSH}$ were also found among diagnostic groups of male subjects $(F[2,39]=$ $5.56, p<0.008$ ), with paired comparisons significant only between the AD and depressed groups $(p<0.05)$ (Table 4$)$.

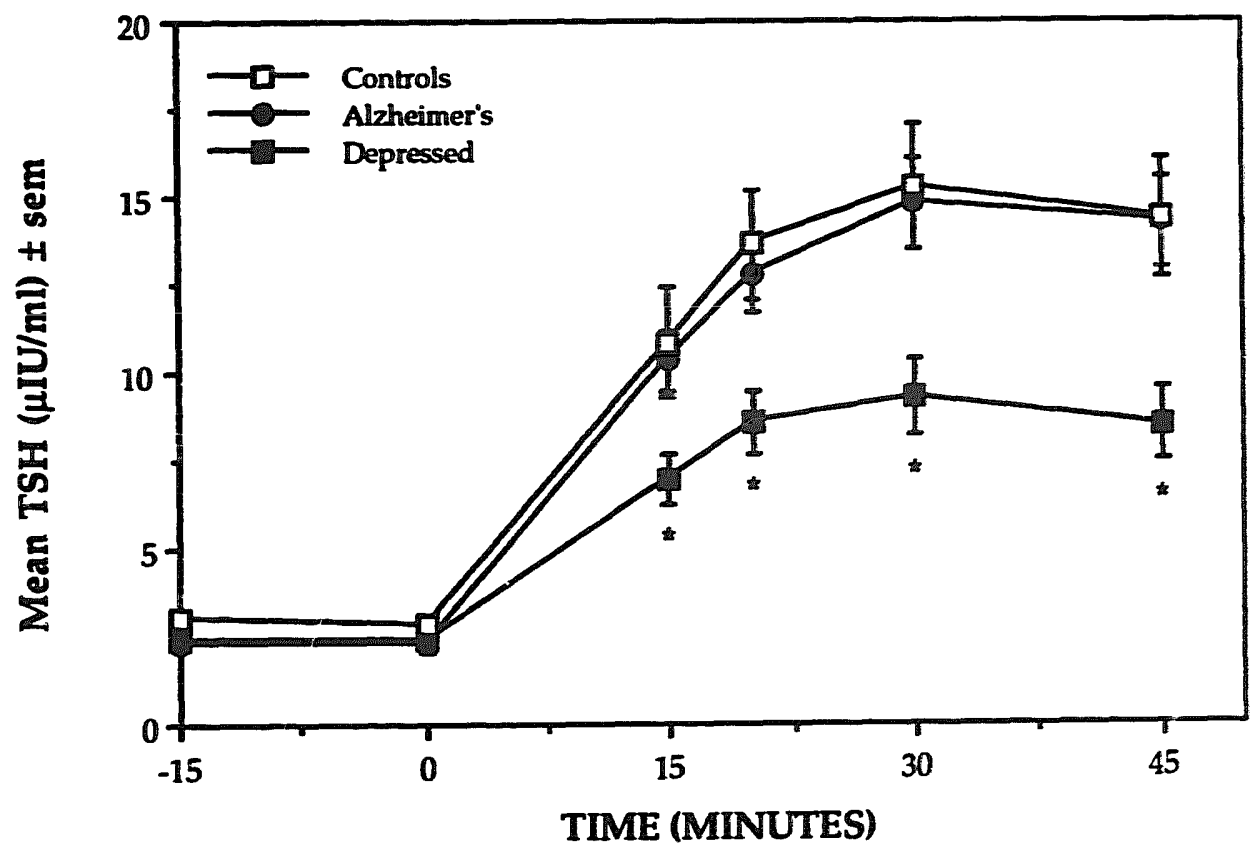

Figure 1. TSH responses to TRH across time in AD patients, depressed patients, and elderly controls. ${ }^{*} p<0.05$, different from $\mathrm{AD}$ patients and controls. 
Table 3. Baseline Thyroid Function Tests and Ratings on Patients with Blunted TSH Response $(\Delta \operatorname{maxTSH} \leqslant 7 \mu \mathrm{IU} / \mathrm{ml})$ versus Nonblunted TSH Response $(\Delta \operatorname{maxTSH}>7 \mu \mathrm{IU} / \mathrm{ml})^{a}$

\begin{tabular}{|c|c|c|c|c|c|c|}
\hline & $\begin{array}{c}\Delta \max T S H^{b} \\
(\mathrm{All} / \mathrm{ml})\end{array}$ & $\begin{array}{c}\text { TSH } \\
(\mu \mathrm{IU} / \mathrm{ml})\end{array}$ & $\begin{array}{c}T_{4} \\
(\mu g / d l)\end{array}$ & $\begin{array}{c}\mathrm{FT}_{4} \\
(\mathrm{ng} / \mathrm{dl})\end{array}$ & $\begin{array}{c}T_{3} \\
(n g / d l)\end{array}$ & $\begin{array}{c}\text { Global } \\
\text { Deterioration } \\
\text { Scale }\end{array}$ \\
\hline \multicolumn{7}{|l|}{ Alzheimer's } \\
\hline Blunted $(n=11)$ & $5.0 \pm 1.8$ & $2.1 \pm 1.5$ & $8.2 \pm 0.8$ & $1.5 \pm 0.3^{r}$ & $123.1 \pm 38.2$ & $4.8 \pm 1.0^{4}$ \\
\hline \multirow[t]{2}{*}{ Nonblunted $(n=29)$} & $15.4 \pm 6.8$ & $2.8 \pm 1.5$ & $7.7 \pm 1.3$ & $1.3 \pm 0.3$ & $126.9 \pm 26.6$ & $4.3 \pm 0.9$ \\
\hline & & & & & & $\begin{array}{l}\text { Hamilton } \\
\text { (17 item) }\end{array}$ \\
\hline \multicolumn{7}{|l|}{ Depressed } \\
\hline Blunted $(n=7)$ & $4.0 \pm 1.9$ & $1.7 \pm 0.8$ & $8.9 \pm 1.3$ & $1.9 \pm 0.2^{d}$ & $123.9 \pm 23.9$ & $25.3 \pm 9.8$ \\
\hline Nonblunted $(n=10)$ & $9.6 \pm 2.7$ & $2.9 \pm 0.9$ & $8.6 \pm 1.8$ & $1.6 \pm 0.2$ & $117.3 \pm 25.5$ & $21.5 \pm 7.2$ \\
\hline
\end{tabular}

In the group of AD patients, $\triangle$ maxTSH correlated significantly with baseline TSH ( $r$ $=0.51, p<0.001, n=37), \mathrm{T}_{4}(r=-0.39, p<0.02, n=37)$, and $\mathrm{FT}_{4}(r=$ $-0.52, p<0.001, n=40$ ). AD patients with a blunted as compared with a nonblunted TSH response tended to be more severely demented as measured by the GDS (Table 3) and the Global Functional Impairment Scale (blunters $=8.9 \pm 2.0$, nonblunters $=6.9$ $\pm 1.8 ; t=-2.5, p<0.01$, df $=29$ ). $\Delta$ maxTSH did not correlate with measures of depression. $T_{3}$ correlated with the Global ratings of depression $(r=0.49, p<0.01, n$ $=26)$, anxiety $(r=0.42, p<0.03, n=26)$, and sadness $(r=0.47, p<0.02, n$ $=26) . \mathrm{FT}_{4}$ and CSF MHPG correlated at a trend level of significance $(r=0.33, p<$ $0.1, n=25$ ). Of the severity and behavioral measures, CSF MHPG correlated at a trend level of significance with two measures of dementia severity, the $\operatorname{CDR}(r=0.34, p<$ $0.07, n=29)$ and the GDS $(r=0.36, p<0.06, n=28)$. There were no correlations between $\Delta \max T S H$ and CSF monoamine metabolites or CSF SLI.

Table 4. Gender Differences in TSH Response and Baseiine Thyroid Function Tests ${ }^{a}$

\begin{tabular}{|c|c|c|c|c|c|c|}
\hline $\begin{array}{l}\text { Blunted TSH } \\
(\mu \mathrm{IU} / \mathrm{ml})\end{array}$ & & $\begin{array}{c}\Delta \max T S H \\
(\mu \mathrm{IU} / \mathrm{ml})\end{array}$ & $\begin{array}{c}\text { TSH } \\
(\mu \mathrm{IU} / \mathrm{ml})\end{array}$ & $\begin{array}{c}T_{4} \\
(\mu \mathrm{g} / \mathrm{dl})\end{array}$ & $\underset{\text { (ng/dl) }}{\mathrm{FT}_{4}}$ & $\begin{array}{c}T_{3} \\
\text { (ng/dl) }\end{array}$ \\
\hline Alzheimer's & & - & & & & \\
\hline Male & $5 / 25(20.0 \%)$ & $13.6=7.6^{c}$ & $2.6 \pm 1.3$ & $7.6 \pm 1.3$ & $1.4 \pm 0.3$ & $123.4 \pm 23.5$ \\
\hline $\begin{array}{c}\text { Female } \\
\text { Depressed }\end{array}$ & $6 / 15(40.0 \%)$ & $11 . + \pm 7.3$ & $2.6 \pm 1.8$ & $8.1 \pm 1.0$ & $1.3 \pm 0.2$ & $122.5 \pm 29.4$ \\
\hline Male & $5 / 8 \quad(6 ?=5 \%)$ & $5.3 \pm 3.1$ & $2.3 \pm 1.1$ & $7.5 \pm 1.4$ & $1.8 \pm 0.4$ & $113.2 \pm 17.5$ \\
\hline Female & $\therefore$ (33.3\%) & $8.7 \pm 3.3^{d}$ & $2.5 \pm 1.1$ & $9.6 \pm 1.0$ & $1.8 \pm 0.2$ & $125.6 \pm 28.3$ \\
\hline \multicolumn{7}{|l|}{ Normals } \\
\hline Male & $1 / 9 \quad(11.1 \%)$ & $9.6 \pm 3.6^{e}$ & $2.9 \pm 1.0$ & $7.5 \pm 1.2$ & $1.4 \pm 0.3$ & $127.4 \pm 21.9$ \\
\hline Female & $0 / 5$ & $17.8 \pm 6.7$ & $31 \pm 1.0$ & $7.7 \pm 1.4$ & $1.4 \pm 0.5$ & $101.8 \pm 6.4$ \\
\hline
\end{tabular}

${ }^{\circ}$ Data are expressed as mean \pm SD.

${ }^{b} \Delta \max \mathrm{TSH} \leqslant 7 \mu \mathrm{IU} / \mathrm{ml}$.

$c p<0.05$ different from depressed men.

${ }^{d} p<0.05$ different from female controls.

e $p<0.05$, different from female controls. 
In the AD patients with a presenile as compared with senile onset of symptoms, there was no difference in $\Delta$ maxTSH or baseline TFTs. Age correlated with $\Delta \max T S H(r=$ $-0.37, p<0.02$ ) within the group of AD patients, and not within the major depression or control groups. Within the AD group, age and $\triangle \max T S H$ correlated significantly for men $(r=-0.46, p<0.02)$; for women the relationship was not significant $(r=-0.22$, $p<0.44)$.

Within the group of depressed patients, there were no correlations among measures of depression, CSF monoamine metabolites, or CSF SLI and $\triangle$ max TSH or other thyroid measures. Within the group of depressed patients with a blunted TSH response, $\triangle$ maxTSH correlated significantly only with baseline TSH $(r=0.73, p<0.05, n=8)$. In the group of normal controls (excluding the one with a blunted response), there were no correlations between $\Delta$ maxTSH and baseline TFTs.

\section{Discussion}

Our finding of an increased rate of blunting on the TRH stimulation test and a lower mean $\triangle$ maxTSH in patients with major depression as compared with normals is consistent with the findings of most previous studies (Loosen 1987). A trend towards an increase in the rate of blunted responses in patients with $A D$ is consistent with some (Sunderland et al 1985; Thomas et al 1987) but not all prior studies (El Sobky et al 1986; Peabody et al 1986; Lampe et al 1988; Franceschi et al 1988; Dysken et al 1990). Reasons for such discrepant results may include the heterogeneity of patients with $A D$, the study of patients at different stages of the illness, the small number of patients used in some of the studies, and the inclusion of subjects with slight baseline TFT abnormalities. Also, some studies included only male subjects (Lampe et al 1988; Peabody et al 1986), and men have generally been shown to have a lower $\triangle \max T S H$ than women with age (Snyder and Utiger 1972; Sunderland et al 1985; Targum et ai 1989; Dysken et al i990), therefore making any differences between $\mathrm{AD}$ and control subjects more difficult to discern.

In our study, the AD patients with a blunted TSH response were more severely demented as measured by the GDS (at a trend level of significance) and the Global Functional Impairment Scale $(p<0.01)$ than those with a nonblunted response. We had previously reported a trend towards a correlation between increased dementia severity and TSH blunting in a different patient group (Sunderland et al 1985), though other studies have not found such a relationship (Franchesi et al 1988; Dysken et̂ al 1990).

In our study, as in most prior studies, no correlation was found between clinical measures of depression and $\triangle \max T S H$ (Loosen 1987). Consistent with our findings, depressed patients with a blunted TSH response have been shown in prior studies to have a lower basal TSH compared with patients whose response is normal or increased (Loosen 1987). Also consistent with some prior studies, the depressed patients had a higher mean $\mathrm{T}_{4}$ level (and $\mathrm{FT}_{4}$ level, significant at the trend level) then the $\mathrm{AD}$ and the control patients (Kirkegaard and Faber 1986). In the AD group, those with a blunted response had an increased $\mathrm{FT}_{4}$, as shown previously in a smaller sample (Sunderland et al 1985), indicating normal feedback inhibition. Hypothalamic neuropathology has been documented in AD (Ishii 1966; McDuff and Sumi 1983), but most studies have not found a significant change in TRH concentration in AD brain (Yates et al 1983; Nemeroff et al 1989) or CSF (Nemeroff, personal communication), though one study did report a decrease in CSF TRH (Oram et al 1981). Interestingly, in one small study, TRH concentration in the amygdala of $\mathrm{AD}$ patients tended to correlate with senile plaque ccunt $(r=-0.67, p<$ 
$0.1, n=7)$ (Biggins et al 1983), which has been shown to be related to dementia severity (Blessed et al 1968).

In our study, within the group of AD patients, women had a rate of blunting twice that of men though this was not statistically significant; there were no gender differences in baseline TFTs or other variables. Our findings are most consistent with those of one other report, in which no difference between genders was found (El Sobky et al 1986). This is of interest in that a significant age-related decrease in $\triangle$ maxTSH in men relative to age-matched women (Snyder and Utiger 1972; Sunderland et al 1985; Targum et al 1989) was not seen in these studies in AD subjects, nor in depressed patients in the present study, though age correlated significantly with $\triangle$ maxTSH within the group of male AD patients. Reasons for these findings are unknown. One study of AD patients found that men had a decreased $\triangle$ maxTSH response as compared with women (Dysken et al 1990).

We found no correlations between $\triangle$ maxTSH or baseline TSH and CSF monoamine metabolite levels in any of the subject groups. Prior studies of associations between TSH response and measures of monoamine metabolism in depressed patients have produced conflicting results (Loosen 1987). In general, evidence from human and animal studies indicate that norepinephrine has a stimulatory role and serotonin an inhibitory role in hypothalamic-pituitary-thyroid axis regulation (Loosen 1987).

In the present study, $\mathrm{FT}_{4}$ correlated at a trend level of significance with CSF MHPG within the group of $\mathrm{AD}$ patients, which is consistent with a stimulatory effect of norepinephrine on the thyroid axis and the adjunctive role of thyroid hormones on noradrenergic function (Nemeroff and Evans 1989). Interestingly, in our group of AD patients, $T_{3}$ and $T_{4}$ correlated withmeasures of depression and anxiety. $T_{3}$ is sometimes added to augment antidepressant medication response, presumably through interactions with catecholamines (Nemeroff and Evans 1989).

We found no correlations between $\triangle$ maxTSH or baseline TSH and CSF SLI. Somatostatin has been shown to have an inhibitory effect on TRH-stimulated TSH release, though no study to date has shown a relationship between CSF SLI and blunted TSH response (Loosen 1987).

In summary, the blunted TSH response in some AD patients is consistent with increased inhibition of TSH by relatively high levels of $\mathrm{FT}_{4}$ (Loosen and Prange 1982). The feedback regulation of thyroid hormones appears then to be intact. Why these patients have increased $\mathrm{FT}_{4}$ levels is unknown; the mechanism may involve decreased feedback or increased stimulation of thyroid hormones by some other substance, such as norepinephrine. This would be consistent with our finding of a positive correlation between $\mathrm{FT}_{4}$ and CSF MHPG, which indicates that increased norepinephrine could be contributing to increased $\mathrm{FT}_{4}$ levels. Also, patients with a blunted $\mathrm{TSH}$ response had significantly higher ratings of dementia severity, and dementia severity correlated positively with CSF MHPG, consistent with the findings of Raskind et al (1984).

In the patients with major depression, our findings are consistent with chronic hypersecretion of TRH as an etiology for blunted TSH responses, in that those with a blunted response had a low basal TSH that could be secondary to TSH receptor desensitization (Kirkegaard et al 1979; Banki et al 1988). Also, TRH itself stimulates thyroid hormone release (Griffiths 1985), so TRH hypersection could have contributed to increased $\mathrm{T}_{4}$ and $\mathrm{FT}_{4}$ levels. Increased thyroid hormone levels would further lower TSH levels by feedback inhibition.

A blunted TSH response to TRH in some depressed and a subgroup of AD patients 
appears to be related to different clinical factors in these groups (to dementia severity and possibly age and gender in the AD patients) and to involve some different etiologic factors. Further studies utilizing the TRH stimulation test and other neuroendocrine tests may help to distinguish diagnostic subgroups and to clarify relationships among different neuropsychiatric illnesses.

\section{References}

American Psychiatric Association (1987): Diagnostic and Statistical Manual of Mental Disorders, 3rd ed rev. Washington, DC: American Psychiatric Press.

Banki CM. Bissettc G, Arato M. Nemeroff CB (1988): Elevation of immunoreactive CSF TRH in depressed patients. Am J Psychiatry 145:1526-1531.

Biggins JA, Perry EK, McDermott JR, Smith AI, Perry RH, Edwardson JA (1983): Post mortem levels of thyrotropin-releasing hormone and neurotensin in the amygdala in Alzheimer's disease, schizophrenia, and depression. I Neurol Sci 58:117-122.

Blessed G, Tomlinson BE, Roth M (1968): The association between quantitative measures of dementia and of senile change in the cerebral grey matter of elderly subjects. Br J Psychiatry 114:797-811.

Bunney WE, Hamburg DA (1963): Methods for reliable longitudinal observation of behavior. Arch Gen Psychiatry 9:280-294.

Dysken MW, Falk A, Pew B, Kuskowski M, Krahn DD (1990): Gender differences in TRHstimulated TSH and prolactin in primary degenerative dementia and elderly controls. Biol Psychiatry 28:144-150.

El Sobky A, El Shazly M, Darwish AK, Davies T, Griffin K, Keshaven MS (1986): Anterior pituitary response to thyrotropin releasing hormone in senile dementia (Alzheimer type) and elderly normals. Acte Psychiatr Scand 74:13-17.

Franceschi M, Perego L, Ferini-Strambi L, Smirne S, Canal N (1988): Neuroendocrinological function in Aizheimer's disease. Neuroendocrinology 48:367-370.

Griffiths EC (1985): Thyrotropin releasing hormone: Endocrine and central effects. Psychoneuroendocrinology 10:225-235.

Hamilton M (1960): A rating scale for depression. J Neurol Neurosurg Psychiatry 23:56-62.

Hughes CP, Berg L, Danziger WL, Coben LA, Martin RL (1982): A new clinical scale for the staging of dementia. Br J Psychiatry 140:566-572.

Ishii T (1966): Distribution of Alzheimer's neurofibrillary changes in the brain stem and hypothalamus of senile dementia. Acta Neuropathol 6:181-187.

Kirkegaard C, Faber J (1986): Influence of free thyroid hormone levels on the TSH response to TRH in endogenous depression. Psychoneuroendocrinology 11:491-497.

Kirkegaard C, Faber J, Hummer L (1979): Increased levels of TRH in cerebrospinal fluid from patients with endogenous depression. Psychoneuroendocrinology 4:227-235.

Lampe TH, Plymate SR, Risse SC, Kopeikin H, Cubberley L, Raskind MA (1988): TSH responses to two TRH doses in men with Alzheimer's disease. Psychoneuroendocrinology 13:245-254.

Lawlor BL, Sunderland T, Mellow AM, Murphy DL (1988): Thyroid disease and dementia of the Alzheimer type. Am J Psychiatry 145:533-534.

Loosen PT (1987): The TRH stimulation test in psychiatric disorders: A review. In Nemeroff CB, Loosen PT (eds), Handbook of Clinical Psychoneuroendocrinology. New York: Guilford, pp 336-360.

Loosen, PT, Prange AJ Jr (1982): Serum thyrotropin response to thyrotropin-releasing hormone in psychiatric patients: A review. Am J Psychiatry 139:405-416.

McDuff T, Sumi SM (1983): Subcortical degeneration in Alzheimer's disease. Neurology 33 (suppl 2):159. 
Nemeroff CB, Evans DL (1989): Thyrotropin-releasing hormone (TRH), the thyroid axis, and affective disorder. Ann NY Acad Sci 553:304-310.

Nemeroff CB, Kizer JS, Reynolds GP, Bissette G (1989): Neuropeptides in Alzheimer's disease: A postmortem study. Regul Pept 25:123-130.

Oram JJ, Edwardson J, Millard PH (1981): Investigation of cerebrospinal fluid neuropeptides in idiopathic senile dementia. Gerontology 27:216-223.

Peabody CA, Minkoff JR, Davies HD, Winograd CH, Yesavage J, Tinklenberg JR (1986): Thyrotropin-releasing hormone stinulation test and Alzheimer's disease. Biol Psychiatry 21:553556.

Perry EK (1987): Cortical neurotransmitter chemistry in Alzheimer's disease. In Meltzer HY (ed), Psychopharmacology: The Third Generation of Progress. New York: Raven, pp 887-895.

Raskind MA, Peskind ER, Veith RC, Beard JC, Gumbrecht G, Halter JB (1984): Arch Gen Psychiatry 41:343-346.

Reding M, Haycox J, Blass J (1985): Depression in patients referred to a dementia clinic: A threeyear prospective study. Arch Neurol 42:894-896.

Reifler BV, Larson E, Teri L, Poulsen M (1986): Dementia of the Alzineimer's type and depression. J Am Geriatr Soc 34:855-859.

Reisberg B, Ferris SH, de Leon MJ, Crook T (1982): The Global Deterioration Scale for assessment of primary degenerative dementia. Am J Psychiatry 139:1136-1139.

Rubinow DR (1986): Cerebrospinal fluid somatostatin and psychiatric illness. Biol Psychiatry 21:341-365.

Scheinin M, Chang W-H, Kirk KL, Linnoila M (1983): Simultaneous determination of 3-methoxy4-hydroxyphenylglycol, 5-hydroxyindoleacetic acid and homovanillic acid in cerebrospinal fluid with high performance liquid chromatography using electrochemical detection. Anal Biochem 131:246-253.

Snyder PJ, Utiger RD (1972): Response to thyrotropin releasing hormone (TRH) in normal man. $J$ Clin Endocrinol Metab 34:380-385.

Sunderland T, Tariot PN, Mueller EA, Newhouse PA, Murphy DL, Cohen RM (1985): TRH stimulation test in dementia of the Alzheimer type and elderly controls. Psychiatry Res 16:269275.

Sunderland T, Alterman IS, Yount D, et al (1988a): A new scale for the assessment of depressed mood in demented patients. Am J Psychiatry 145:955-959.

Sunderland T, Hill JL, Lawlor BA, Molchan SE (1988b): NIMH Dementia Mood Assessment Scale (DMAS). Psychopharmacol Bull 24:747-753.

Targum SD, Marshall LE, Magac-Harris K, Martin D (1989): TRH tests in a healthy elderly population: Demonstration of gender differences. J Am Geriatr Soc 37:533-536.

Thomas DR, Hailwood R, Harris B, Williams PA, Scanlon MF, John R (1987): Thyroid status in senile dementia of the Alzheimer type (SDAT). Acta Psychiatr Scand 76:158-163.

Warner MD. Vinogradov S, Peabody CA, et al (1990): TRH/LHRH stimulation test and Alzheimer's disease. Biol Psychiatry 28:362-365.

Yates CM. Harmar AJ, Kosic R, st al (1983): Thyrotropin-releasing hormone, luteinizing hormonereleasing hormone and substance $\mathbf{P}$ immuno-reaciivity in postmortem brain from cases of Alzheimer-type dementia and Downs' syndrome. Brain Res 258:45-دz. 